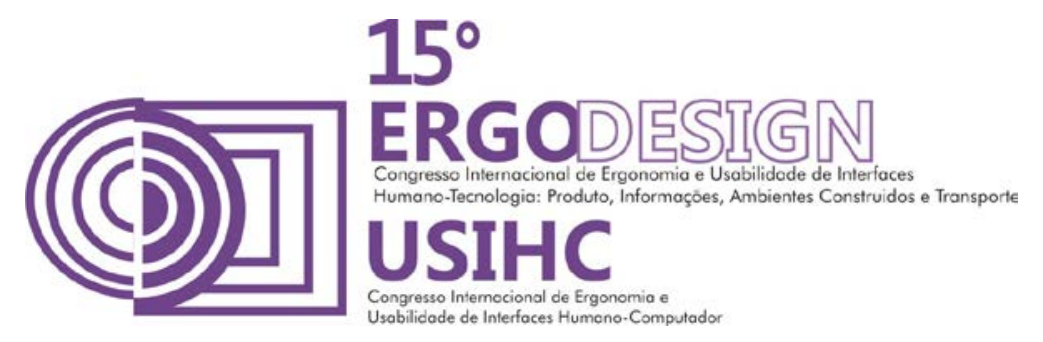

\title{
ARQUITETURA DA INFORMAÇÃO E USABILIDADE: ANÁLISE DO PROCESSO DE CADASTRO DE AUTOR E SUBMISSÃO DE UM ARTIGO NO PERIÓDICO ELETRÔNICO BIBLIOCANTO DA UFRN
}

\author{
INFORMATION ARCHITECTURE AND USABILITY: ANALYSIS OF THE \\ AUTHOR REGISTRATION AND SUBMISSION PROCESS OF AN \\ ARTICLE IN THE ELETRONIC PERIODICAL BIBLIOCANTO OF UFRN
}

SANTA ROSA, José Guilherme (1);

PINHO, Andre Luis Santos de (2); CARVALHO, Caio Vitoriano de Nunes e (3); GUSMÃO, Eduardo Henrique Olímpio de (4);

SALES JÚNIOR, Francisco Monteiro de (5);

FONSECA JÚNIOR, José Nivaldo (6);

MAIA, Maria Aniolly Queiroz (7)

(1) UFRN, Doutor, e-mail: jguilhermesantarosa@gmail.com;

(2) UFRN, Doutor, e-mail: pinho@ccet.ufrn.br;

(3) UFRN, Especialista, e-mail: caiovitoriano@yahoo.com.br;

(4) UFRN, Especialista, e-mail: eduardogusmao@gmail.com;

(5) UFRN, Especialista, e-mail: fmsjunior@yahoo.com.br;

(6) UFRN, Especialista, e-mail: nivaldofir@hotmail.com;

(7) UFRN, Especialista, e-mail: aniollymaia@gmail.com

\begin{abstract}
RESUMO
Este trabalho discorre sobre o processo de cadastro de autor e submissão de um artigo no periódico BiblioCanto, no Portal de Periódicos Eletrônicos da Universidade Federal do Rio Grande do Norte. A pesquisa com grupo de bibliotecários da UFRN envolveu análise contextual e entrevista em que foram avaliadas a arquitetura da informação e a usabilidade do periódico. Com os dados, foi possível identificar diversas falhas de design nos formulários de cadastro de autor e submissão de artigo neste Periódico. Com base nas informações obtidas, foram propostas melhorias, refinando o design e a arquitetura da
\end{abstract}




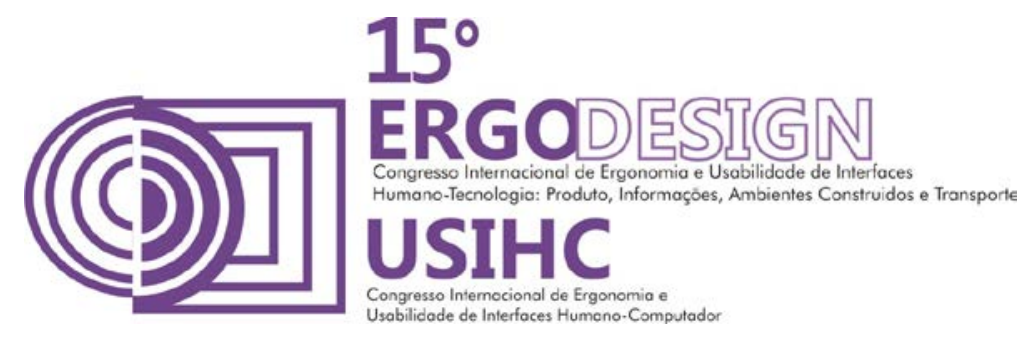

informação do periódico.

Palavras-chave: Arquitetura da Informação, Usabilidade, Interação Humano-Computador, Bibliocanto.

\section{ABSTRACT}

This paper discourse about the author cadastre process and the article submission in a BiblioCanto Periodical inside of the Portal de Periódicos Eletrônicos da Universidade Federal do Rio Grande do Norte. The research with a librarian group of the University involved contextual analysis and interview in witch was evaluable the information architecture and the journal usability. With the data, was possible identify many design failures in the author cadastre formulary and article submission in this Periodical. Based in information obtained, were proposed improvements, refining the periodical's design and the information architecture.

Keywords: Information Architecture, usability, human-computer interaction, Bibliocanto.

\section{INTRODUÇÃO}

Promover a disseminação do conhecimento sempre foi um desafio para os estudiosos acadêmicos e cientistas. Contudo, sua publicação era limitada à disponibilidade de publicações impressas, o que, nem sempre permitia sua circulação em ampla escala.

A produção do conhecimento científico ocorre principalmente nas universidades e instituições de pesquisa e a comunicação desse conhecimento compreende um conjunto de atividades que engloba a produção, disseminação e uso da informação desde o início onde as ideias da pesquisa são geradas até o momento da aceitação dos resultados como parte do conhecimento científico. (LEITE; COSTA apud ROSETTO, 2013, p. 8).

Norteados por esta premissa, este trabalho tem o objetivo de analisar e avaliar a arquitetura da informação e a usabilidade no processo de cadastro de autor e submissão de um artigo no periódico BiblioCanto do Portal de Periódicos Eletrônicos da Universidade Federal do Rio Grande do Norte (UFRN).

Junto com Rosetto (1997 e 2013), Ferreira e Caregnato (2008) e Alves (2010), traçou-se um breve perfil sobre as revistas eletrônicas e seu papel no processo de popularização dos conhecimentos produzidos por cientistas, profissionais e estudiosos.

A metodologia da pesquisa ora apresentada dá-se sob a forma de Análise Contextual e uma Entrevista, na qual os participantes (profissionais bibliotecários que concluíram ou estão cursando pós-graduação stricto sensu) foram solicitados a desenvolver determinadas tarefas para cadastro e submissão de artigo na Revista Eletrônica BiblioCanto que integra o Portal de Periódicos Eletrônicos da UFRN.

Com os resultados da análise pretende-se esclarecer alguns questionamentos, a saber: o que pensam os usuários do sistema? Este é realmente útil da forma como se apresenta? Quais pontos dificultam a realização das tarefas? 


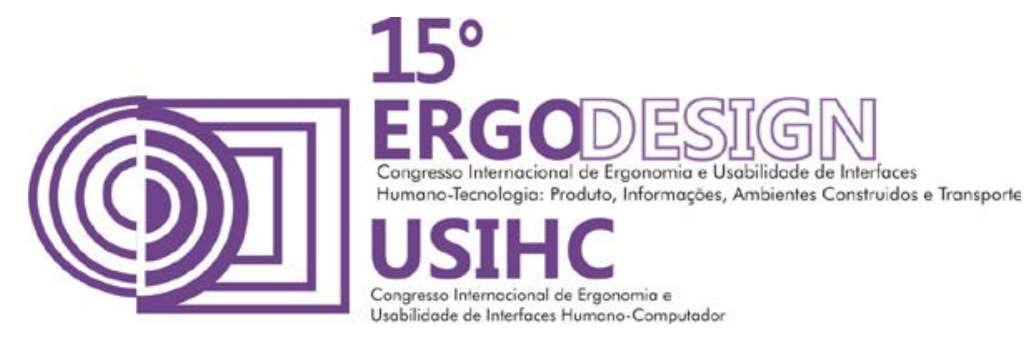

\section{INTERAÇÃO HUMANO-COMPUTADOR}

A interação humano-computador (IHC) é uma área distinta dedicada à compreensão da relação entre pessoas e sistemas computacionais, fornecendo recursos para o desenvolvimento de sistemas e produtos interativos a partir de uma perspectiva centrada no usuário, oferecendo, dessa forma, uma melhor resposta às necessidades do cliente.

Segundo I. Scott Mackenzie (2012, p. 2):

[...] a disciplina IHC surgiu na década de 1980, porém tem raízes em disciplinas mais antigas e uma das que mais a representa é a ergonomia, em que se preocupa com as capacidades humanas, limitações, performance e com o design de sistemas que são eficientes, seguros, confortáveis e até agradáveis para os seres humanos.

Para David Benyon (2011, p. 9), o designer deve levar em consideração a interação humanocomputador como um todo, em que é necessária uma série de habilidades que permitam:

- Estudar e entender as atividades e aspirações das pessoas e dos contextos dentro dos quais uma determinada tecnologia pode se revelar útil e, portanto, gerar requisitos para tecnologias;

- Conhecer possibilidades oferecidas pelas tecnologias;

- Pesquisar e projetar soluções tecnológicas que combinem com as pessoas, com as atividades que elas querem realizar e com os contextos nos quais essas atividades acontecem;

- Avaliar designs alternativos e iterar (fazendo mais pesquisa e mais design) até chegar a uma solução.

Segundo Shneiderman (1997), problemas no projeto de uma interface podem causar graves danos e dificuldades na realização dos trabalhos para uma organização. Contudo, poucas levam em consideração este fato quando planejam as aplicações. Benyon reconhece como dispendioso, em termos de design, o aspecto de ser centrado no humano, no que diz respeito ao custo e tempo de implementação do projeto, de modo que os clientes questionam se é realmente viável o investimento na participação das pessoas durante as fases do projeto. Porém, Benyon (2011, p. 11, tradução nossa) destaca pela vantagem da abordagem centrada no humano e cita razões como:

- Retorno do investimento: envolver as pessoas na elaboração do projeto garante a aceitabilidade, permitindo que os usuários sejam mais produtivos e precisem de menos material para treinamento;

- Segurança: o processo de projetar para pessoas e seus contextos ajuda evitar erros que poderiam ser cometidos na interação com o sistema;

- Ética: cada vez mais os sistemas utilizam o compartilhamento de dados e as pessoas devem possuir o controle sobre a privacidade e de como suas informações serão disponibilizadas;

- Sustentabilidade do projeto: o design centrado no humano deve reconhecer a diversidade e aprimorar os valores humanos. 


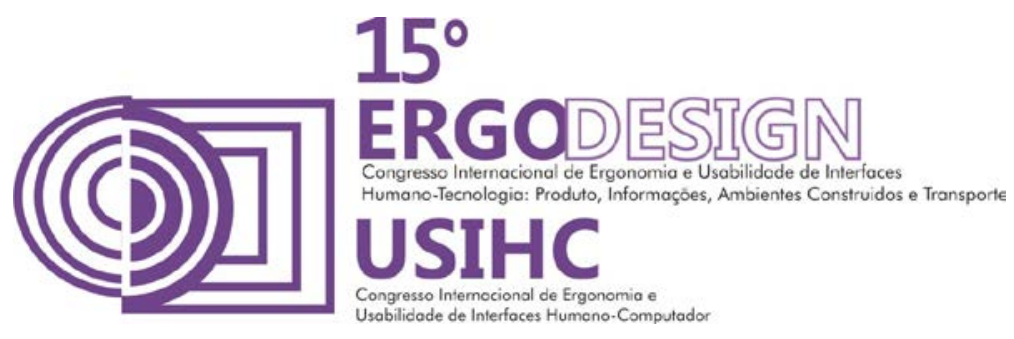

\section{ARQUITETURA DA INFORMAÇÃO}

Descreve-se a arquitetura da informação (Al) como uma metodologia na organização de ambientes de informação, para isto a Al estrutura e organiza a informação na tentativa de esclarecer o complexo para os diversos tipos de usuários.

Segundo Benyon (2011), a arquitetura de informação para sites se refere à forma de organização e descrição do conteúdo, através de taxonomias na organização, rotulagem de itens, descrições e formas de apresentação da arquitetura.

De acordo com Rosenfield e Morville (2006, p. 4), uma tentativa de definir a Al pode ser iniciada sobre os seguintes aspectos:

1. O projeto estrutural de ambientes compartilhados de informação;

2. A combinação de organização, rotulagem, pesquisa e sistema de navegação em sites e intranets;

3. A arte e a ciência de moldar informações e experiências para apoiar usabilidade e a facilidade que o usuário tem de achar a informação que procura;

4. Uma disciplina emergente e comunidade de prática focada em trazer princípios de design e arquitetura para a paisagem digital.

Alguns autores destacam a dificuldade de se organizar as informações devido à diversidade do publico alvo, onde a experiência particular de cada usuário se mostra um desafio na obtenção de uma arquitetura de informação robusta, que sirva para múltiplos interesses. Segundo Rosenfield e Morville (2006, p. 4), "nenhum rótulo ou definição captura totalmente o significado de um documento, e dois usuários não têm a mesma compreensão ou experiência em um documento específico, definição ou rótulo da mesma maneira".

\section{USABILIDADE}

A usabilidade corresponde ao estudo de como os seres humanos se relacionam com qualquer produto. "As práticas de usabilidade poderiam ser implementadas em tudo, de uma torradeira a uma maçaneta, ou até mesmo à embalagem de ambos." (LOWDERMILK, 2013, p. 26).

"É importante salientar que um problema de usabilidade ocorre durante a interação, atrapalhando o usuário na relação de sua tarefa, mas tem sua origem em um problema de ergonomia de interface." (CYBIS; BETIOL; FAUST, 2010, p. 202).

É um atributo de qualidade ao produto que confere se uma interface é fácil de utilizar, autoexplicativa e se também o usuário chega a níveis de satisfação, eficiência e eficácia satisfatórios conforme o NBR 9241:11. Preocupadas com tais características as interfaces cada vez mais proporcionam aos usuários uma experiência completa e ideal, criando um maior grau de familiaridade com os sistemas de memorização das informações.

Para Rubin (1994), inconsistências podem ser facilmente detectadas em um sistema a partir da avaliação de especialistas. Contudo, são os usuários que podem verbalizar as dificuldades a 


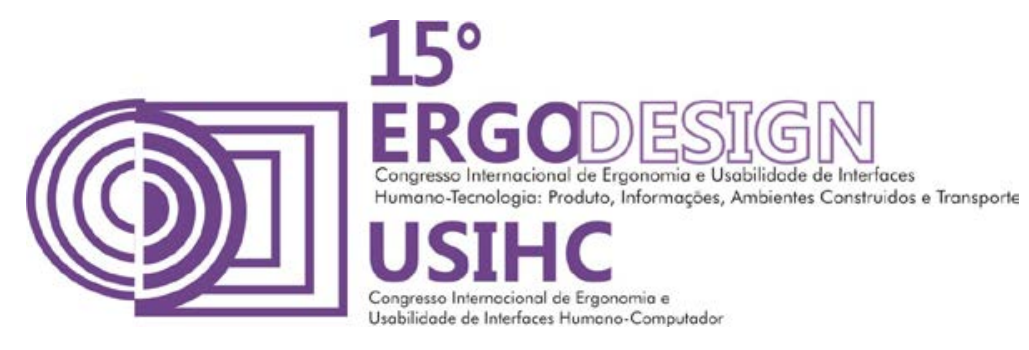

partir da realização de tarefas, baseados em seus desempenhos e preferências, de modo que os obstáculos no sistema sejam identificados.

\section{REVISTAS ELETRÔNICAS E O SISTEMA ELETRÔNICO DE EDITORAÇÃO DE REVISTAS (SEER)}

A comunicação, a interação, a troca de informações, há muito se dá como um processo pelo qual as pessoas buscam, incessantemente, o conhecimento. "Assim, para essa constante busca de algo que possa alimentar esse impulso básico, a ação de comunicação tornou-se uma atividade essencial e inevitável, proporcionando constante provisão e assimilação de novas informações." (ROSETTO, 1997, p. 1).

No espaço acadêmico, a produção científica é responsável por mudanças no processo de disseminação do conhecimento gerado dentro de universidades e institutos de ciências. Organizar toda esta produção passou a ser uma necessidade para a geração de conhecimento confiável.

Até o século XVII, a comunicação científica entre os pesquisadores era feita por meio de cartas, publicações esporádicas de panfletos e livros, não havendo um centro responsável pela transmissão dessas publicações. Devido à informalidade, não havia reconhecimento das informações contidas nessas publicações por outros cientistas. "Com o passar do tempo, a necessidade de preservar o conhecimento gerado por meio da ciência fez com que os pesquisadores passassem a publicar as suas descobertas em canais formais de comunicação". (ZIMAN apud FERREIRA; CAREGNATO, 2008, p. 172).

Esta organização deu-se através da criação e produção de revistas acadêmicas que se tornaram, então, os meios mais confiáveis para divulgação da produção científica. "Como a informação científica precisa ser divulgada de forma rápida e com confiabilidade, os periódicos científicos revelaram-se como uma das melhores opções para a publicação de resultados de novos estudos." (FERREIRA; CAREGNATO, 2008, p. 172). Contudo, os veículos impressos (revistas, jornais, periódicos, etc.) especializados tornaram-se, com o passar dos anos, onerosos e, ainda, fisicamente distantes.

Com o advento da Internet, o processo de produção e difusão do conhecimento sofreu grandes mudanças. Atualmente, não se pode pensar neste sem integrá-lo às mídias digitais on line, pois "a tecnologia vem proporcionando profundas transformações nos procedimentos de produção, transmissão e uso da informação." (ROSETTO, 1997, p. 1). Ela ainda desempenha função importante, como afirma Bauer apud Macedo-Rouet (2003, p. 103), ao dizer que o papel da Internet "é fundamental, sendo uma das marcas do 'ciclo de expansão' da divulgação científica que vivemos atualmente".

Complementando este raciocínio sobre a importância da tecnologia e da Internet como veículos de propagação do conhecimento, Ferreira e Caregnato (2008, p. 173) acertam que:

Com os avanços tecnológicos e a diminuição das barreiras relacionadas à utilização e aceitação dos recursos eletrônicos por autores, leitores e editores, as revistas eletrônicas na Web surgiram como uma alternativa para aumentar a rapidez na disseminação e ampliar a distribuição da informação entre os cientistas, mantendo-se os critérios de qualidade. 


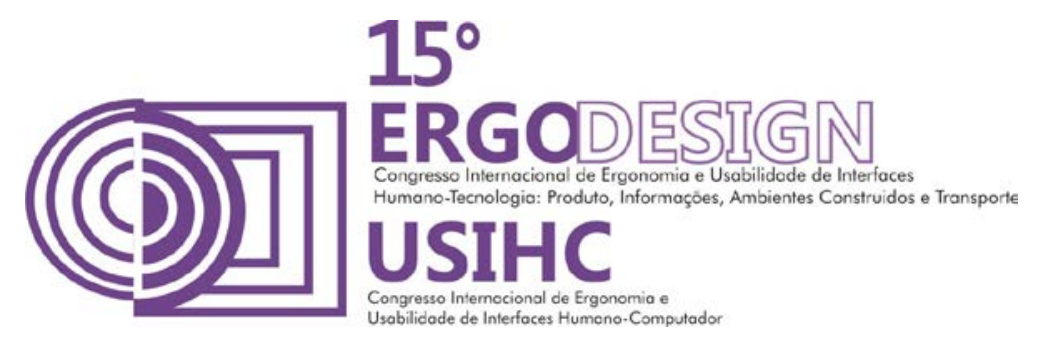

A virtualização das pesquisas acadêmicas proporcionou um alcance sem medidas dos artigos científicos. Cada vez mais, multiplica-se o número de indivíduos que se utilizam dos documentos disponibilizados na rede para nortearem suas pesquisas. Sobre isto, Ferreira e Caregnato (2008, p. 173) dizem que "uma das características desejadas do periódico eletrônico é a maior rapidez em disponibilizar os artigos para o público, tendo em vista que o processo de impressão e distribuição é inexistente na publicação on-line."

Associado ao alto grau de confiabilidade de revistas e periódicos eletrônicos, a facilidade de acesso aos arquivos digitais confere ao sistema virtual de consulta uma forma prática e rápida de obter informação, fazendo com que o usuário evite extensas pesquisas em livros e revistas impressos. Somam-se a isto, outras vantagens elencadas por Ferreira e Caregnato (2008, p. 172), a saber:

Um número maior de pessoas pode ler e acessar instantaneamente e simultaneamente os artigos; o tempo e custos com o processo impresso podem ser minimizados; as bibliotecas podem dispor de mais espaço nas estantes, pois o grande volume de papel diminuiu de maneira significativa.

Ainda, complementam apontando pontos que podem ser considerados como não tão vantajosos, dizendo que:

O acesso livre às publicações aumenta o número de leitores atingidos, bem como a rapidez no fornecimento da informação, porém armazenar arquivos em meio eletrônico também implica custos com recursos materiais e humanos, equipamentos, equipe de editoração, manutenção da página e servidores que armazenem os arquivos referentes à publicação. Sem essa estrutura mínima, a revista pode tornar-se inviável. (FERREIRA; CAREGNATO, 2008, p. 173).

Dentro desta perspectiva, o Sistema de Eletrônico de Editoração de Revistas (SEER) surge como um ambiente digital responsável pela editoração de documentos (artigos, resumos, resenhas, entre outros) e é amplamente utilizado por pesquisadores, cientistas, profissionais e estudantes.

Em sua plataforma inicial, o SEER foi uma adaptação do Open Journal Systems, um sistema de software livre criado pela Universidade British Columbia do Canadá. No Brasil, coube ao Instituto Brasileiro de Informação em Ciência e Tecnologia (IBICT) a tradução e customização aos padrões da pesquisa nacional, objetivando "organizar a informação científica por meio do gerenciamento das atividades editoriais e, consequentemente, divulgação em meio eletrônico." (MORENO apud ALVES, 2010, p. 110).

Alves (2010) lembra, ainda, que este aumento nas publicações em periódicos eletrônicos vem sempre reforçado pela necessidade de propagação da informação, do conhecimento científico e, também, pela facilidade criada pela tecnologia no processo de publicação.

A simplificação do processo de publicação de artigos tornou o SEER uma ferramenta muito utilizada no meio acadêmico-científico. O software "automatiza praticamente todo o processo editorial de um periódico cientifico, sendo uma alternativa ao processo tradicional de publicação de periódicos, buscando facilitar e agilizar a troca de informações entre autores, revisores, editores e o processo de revisão dos pares." (ALVES, 2010, p. 111). 


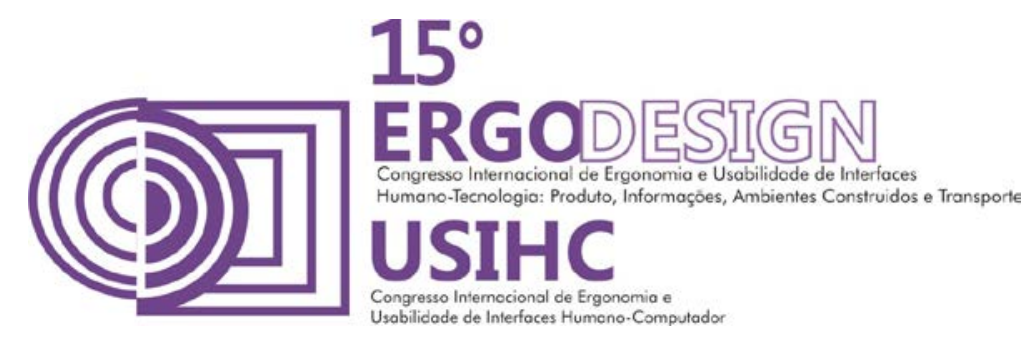

Assim, percebe-se um incremento considerável nos arranjos produtivos do meio acadêmicocientífico em consequência da integração tecnológica possibilitada pelos softwares e a Internet à produção de artigos científicos.

\section{PORTAL DE PERIÓDICOS ELETRÔNICOS DA UFRN}

O Portal de Periódicos Eletrônicos da Universidade Federal do Rio Grande do Norte corresponde a um repositório digital que abriga as revistas científicas dessa instituição. Esse repositório utiliza o Sistema Eletrônico de Editoração de Revistas para a gestão e editoração dos periódicos. O portal foi criado em dezembro de 2009 através da Resolução 237/09 CONSEPE e passou a funcionar em março de 2010. (PORTAL DE PERIÓDICOS ELETRÔNICOS DA UFRN, 2010).

Para fazer parte do portal, os responsáveis pelas revistas devem efetuar a leitura da Política Editorial do Portal, submeter um projeto editorial à comissão gestora, este será avaliado pelos membros da comissão e, em caso, de parecer favorável, a equipe responsável pela revista recebe treinamento da ferramenta SEER da equipe do setor de Repositórios Digitais da Biblioteca Central Zila Mamede e passam a ser monitorados por esta mesma equipe.

O portal contempla diversos periódicos, um deles corresponde ao BiblioCanto que será bordado a seguir, objeto de estudo deste artigo.

\section{BIBLIOCANTO}

O BiblioCanto é um periódico eletrônico desenvolvido pelo Setor de Informação e Referência da Biblioteca Central Zila Mamede, com o objetivo de divulgar os textos produzidos pela comunidade universitária e o resgate da literatura de um modo geral.

Este periódico circulou desde setembro de 1995 com periodicidade bimensal. No entanto, a partir do ano de 2008, passou a ser editado semestralmente. O mesmo passou a integrar 0 portal a partir do ano de 2011. A visualização e submissão dos documentos existentes neste periódico são abertas à comunidade interna e externa, sendo necessário para quem deseja submeter um documento o desenvolvimento de um cadastro na ferramenta SEER (BIBLIOCANTO, 2011).

O periódico contém apenas uma edição em formato eletrônico que, por sua vez, foi uma compilação dos números que foram lançados em formato impresso, os quais compreendem o período 1994-2001.

\section{METODOLOGIA}

Foi analisada a atividade em um sistema real de cadastro e submissão de artigos no periódico eletrônico BiblioCanto, hospedado no Portal de Periódicos Eletrônicos da Universidade Federal do Rio Grande do Norte (UFRN). O recorte da pesquisa selecionou uma amostra de bibliotecários da instituição, que cursam ou cursaram pós-graduação stricto sensu, avaliados sob o auspício da usabilidade da interação humano-computador (IHC). A metodologia de pesquisa adotada foi a análise contextual de tarefas associada a uma entrevista. 


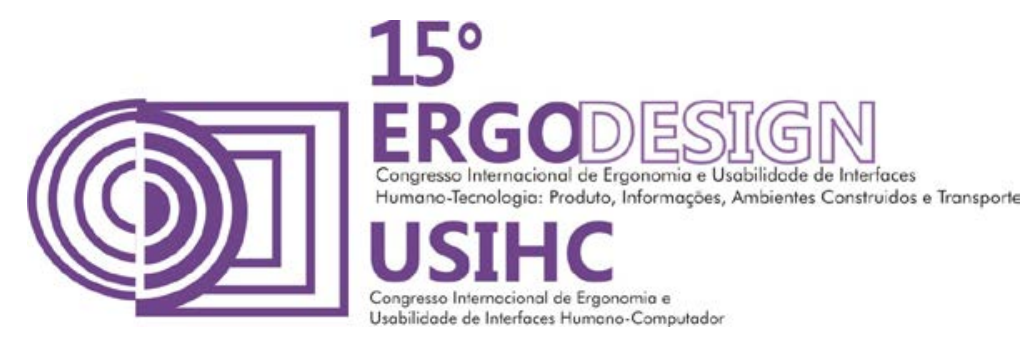

Como não fora possível entrevistar, preliminarmente, os desenvolvedores/projetistas do sistema em que a revista se encontra, já que se trata de um software livre desenvolvido pela Public Knowledge Project (PKP), foi realizada uma rápida avaliação da interface do tipo heurística de usabilidade (NIELSEN, 1993), que pode ocorrer sem a presença dos profissionais em questão. Jakob Nielsen desenvolveu o livro Usability engineering, de 1994, dez qualidades base que toda interface deveria apresentar. Com essa experiência e direcionamento, foi realizado um diagnóstico sobre o sistema de submissão de artigo e cadastramento do periódico BiblioCanto importante para detectar os possíveis problemas de usabilidade junto aos bibliotecários entrevistados.

Assim, após os respondentes assinarem o termo de consentimento livre e esclarecido da pesquisa, registrando concordância, aplicou-se uma entrevista e, paralelamente, registrou-se em áudio e vídeo as interações (telas) dos usuários no sistema da revista, anotando seus passos e caminhos. Todos os sete bibliotecários, 6 (seis) do sexo feminino e 1 (um) do sexo masculino, utilizaram computadores similares e compatíveis com os que usam geralmente no trabalho com sistema operacional da plataforma Microsoft e Internet estável da Biblioteca Central Zila Mamede (BCZM). Com o ambiente controlado, também foi certificado se o grau de instrução em informática nos sujeitos era similar, bem como suas procedências culturais, pelo menos em relação à cidade em que moram. Assim, não houve, de imediato, barreiras em relação à língua ou referências de uso do computador. Todos já haviam navegado na Internet e sabiam seus comandos. Assim, o contexto de investigação seguiu o recomendado por Norman (2006, p. 202):

Tornar fácil determinar as ações possíveis a qualquer momento (fazer uso de coerções); tornar as coisas visíveis, inclusive o modelo conceitual do sistema, as ações opcionais e os resultados das ações; Tornar fácil avaliar o estado atual do sistema; Seguir os mapeamentos naturais entre as intenções e as ações exigidas, entre as ações e o efeito resultante e entre as informações visíveis e a interpretação do estado do sistema.

É pertinente destacar ainda que o documento utilizado para o teste no processo de submissão correspondia a um artigo com um título contendo vinte palavras, resumo com duzentos e vinte e cinco palavras e cinco palavras-chave.

\section{9. $\quad$ ANÁLISE E DISCUSSÃO DOS DADOS}

A maioria dos respondentes não teve problemas em executar as tarefas que foram pedidas. Dos sujeitos investigados, $71 \%$ já utilizara algum sistema eletrônico para submissão de documentos em periódicos e, inclusive, um dos bibliotecários, já conhecia o periódico BiblioCanto. Contudo, foram detectadas situações de considerado esforço cognitivo para identificação de links para se seguir os passos solicitados para o cumprimento da tarefa, bem como inelegibilidade de informações no site. Especificamente, 14\% não teve dificuldade alguma em submeter um documento ao periódico e se cadastrar no sistema, outros 14\% que já conheciam a revista sentiram-se à vontade para manifestar opiniões de melhorias do site, mas o considerou autoexplicativo. Estes sujeitos foram classificados como usuários mais experientes. Os demais participantes tiveram algum tipo de dificuldade em uma ou ambas as etapas (cadastramento e submissão). 


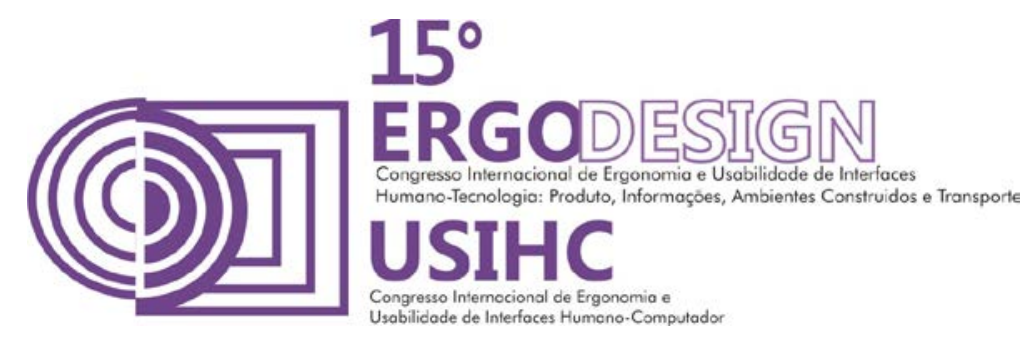

E, dentro dos estudos empíricos de Jakob Nielsen, desenvolvidos na década de 1990, também denominados heurísticas de usabilidade, baseado em propriedades comuns às interfaces, pode-se levantar alguns apontamentos de melhorias do design da página BiblioCanto e sua navegação em questão: quando possível o sistema de evitar a ocorrência de erros e ter design estético e minimalista (evitar o uso de informações irrelevantes), aceleradores para usuários mais experientes e que seja um sistema reconhecível e não de memorização (não obrigando o usuário ter que relembrar todos os passos que fez da última vez).

A seguir são apresentadas, em tópicos, as principais observações dos usuários e discussões decorrentes.

\subsection{Sistema de Rotulação:}

O rótulo do acesso direto ao cadastramento ("cadastro"), no menu de navegação superior, pode ser apresentado com maior destaque, considerando que não demostra ser intuitivo para um dos respondentes. Os rótulos apresentados nos botões de submissão, em geral, precisam ser configurados para possibilitar maior legibilidade. O rótulo "substituir artigo" que é apresentado após a transferência do arquivo aparenta ser, em si, uma opção para a substituição, aparentando ser um link.

\subsection{Sistema de Validação:}

O sistema "captcha" (Completely Automated Public Turing Test to Tell Computers and Humans Apart), ferramenta presente na revista para evitar cadastramentos indesejáveis oriundos da Internet por parte de computadores programados (robôs) pode ser reformulado para evitar dúvidas relacionadas a letras maiúsculas e minúsculas, e diferenciação entre caracteres similares.

\subsection{Feedback:}

O feedback fornecido pelo sistema por ocasião da inserção de dados com formatos incorretos no formulário de cadastramento apresenta mensagem informando onde ocorreu o erro. Com exceção do código de validação, todos os campos preenchidos previamente, incluindo os campos incorretos, são recuperados. Neste contexto, recomenda-se que esta mensagem possa ser apresentada com o uso de tipografia destacada, com fonte de tamanho e cor que a diferencie dos demais rótulos presentes no formulário, proporcionando evidência e intuitividade. Ainda, como o código de validação deverá ser novamente fornecido, o usuário precisa ser informado desta exigência o que pode ser implementado a partir do destaque do próprio campo. Por fim, os campos preenchidos corretamente podem ser apresentados em tonalidade transparente, o que enfatizará os que precisam ser ajustados.

\subsection{Formatação de Campos:}

Cada campo do formulário que exige formato específico, como a presença e/ou ausência de determinados caracteres, bem como uma quantidade mínima destes, pode ter a sua validação realizada por ocasião da própria digitação, em tempo real. Como exemplo, por ocasião do preenchimento do campo "login", caso o usuário tente inserir o caractere equivalente ao 


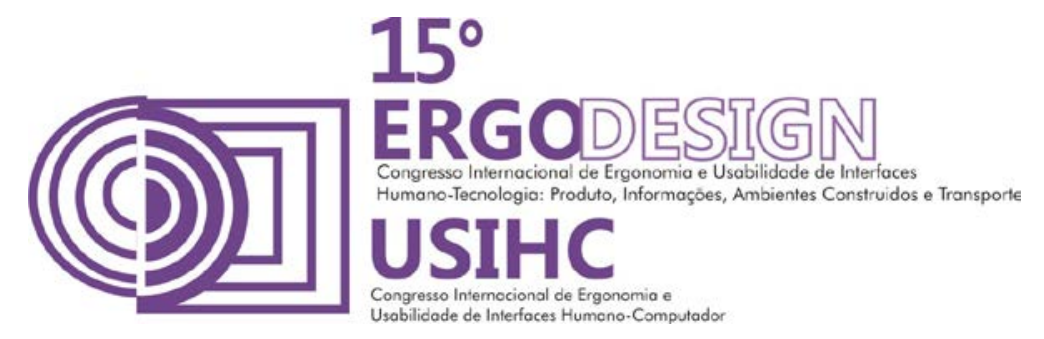

espaçamento, o sistema não deve permitir ou informar de imediato a incompatibilidade em uma mensagem contextual. As instruções presentes nos campos dos sistemas, como a que trata o preenchimento das iniciais do usuário são confusas. Para o referido exemplo, um sujeito identificou a instrução "Joan Alice Smith = JAS" como sendo o nome de alguma revista e não um modelo a ser seguido, conforme pode ser visto na figura 1. Assim, padrões estabelecidos para fornecimento de metadados podem estar mais claros.

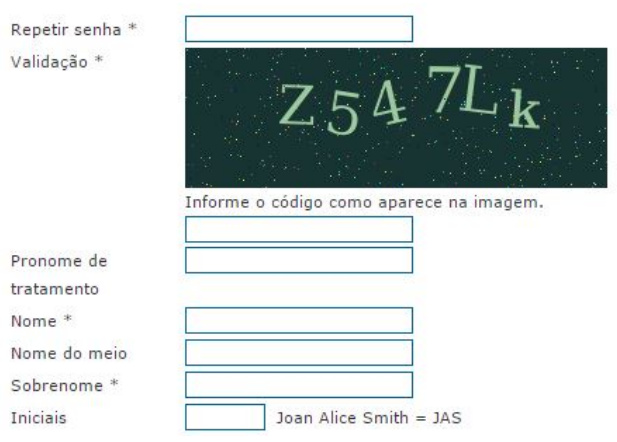

Figura 1 - Recorte de parte de formulário de cadastramento de usuário no sistema SEER. Fonte: os autores.

\subsection{Clareza de Campos:}

Considerando que a tarefa de cadastro no SEER nos testes de usabilidade exige 0 preenchimento de campos obrigatórios e para um perfil de "Editor", o campo "Leitor" disponível proporciona dúvidas ao usuário. Compreendendo que esta opção está relacionada à possibilidade de um usuário pagar pelo acesso ao conteúdo disponibilizado, o que não é o caso para o recorte da investigação realizada, compreende-se que este campo deva ser suprimido no processo de configuração da revista, exigindo-se menor "esforço cognitivo".

\subsection{Obrigatoriedade de Campos:}

Para simplificação do processo inicial de cadastramento, usuários identificaram a importância de serem mantidos apenas os campos de cunho obrigatório. Os campos não identificados como essencialmente necessários nesta etapa podem permanecer habilitados para um registro posterior, em um processo de edição. Vale destacar que essa necessidade do usuário foi externada mesmo com as tarefas solicitadas não prevendo o preenchimento de todos os campos. A seguinte fala possui particular destaque neste contexto: "nas interfaces há muita informação... (...) deveriam ser deixados apenas os campos que possuem asteríscos pois, do contrário, sempre vamos querer preencher tudo". De forma similar, foi recomendado por sujeitos da pesquisa que as fontes gerais das interfaces poderiam ser maiores, pois o atual tamanho dificulta a leitura, conforme fala que se destaca: "(...) deveria existir melhor contraste entre cor de fontes e fundo para melhor visualização de leitura". 


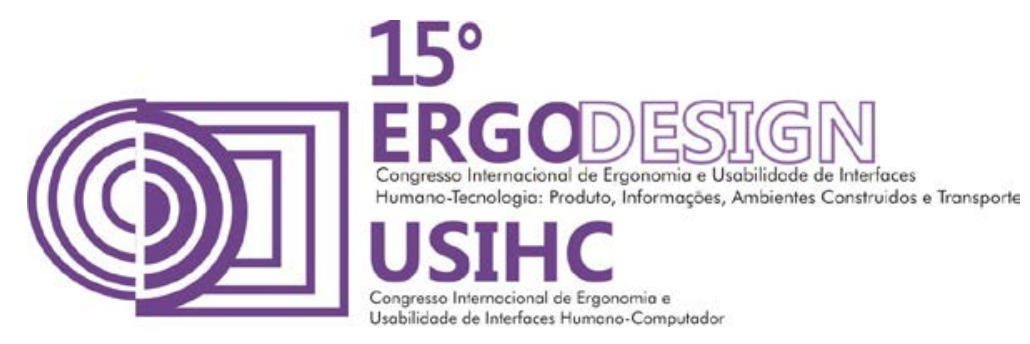

\section{CONSIDERAÇÕES FINAIS}

A maioria dos respondentes considerou a ferramenta autoexplicativa, demonstrando identificação com a mesma, entendendo que é apropriada para o que se destina, apesar de alguma limitação pontual. Contudo, um dos usuários verbalizou que não considera sistema intuitivo em suas ponderações finais.

Conforme Abrahão e Pinho (2002, p. 47), "um dos interesses da Ergonomia é saber o que os trabalhadores realmente fazem, como fazem". A adaptação à realidade tecnológica que vivemos é o que torna a execução de tarefas rotineiras mais amigáveis. Os autores continuam:

O computador, como um instrumento de trabalho, é um mediador entre a ação e o objeto de trabalho. Assumiu-se como pressuposto que o tratamento da informação que ele viabiliza foi responsável por uma 'intelectualização' do trabalho, fruto de um aumento da complexidade ou do papel de certas funções mentais tais como: percepção, memória, representação mental, raciocínio, compreensão e produção de textos. (ABRAHÃO e PINHO, 2002, p. 48).

Avalia-se, de todo modo, que as configurações do sistema utilizadas pelo periódico podem ser melhoradas tornando-se mais amigáveis e mais autoexplicativas, com o aprimoramento do design e de sua arquitetura informacional, já que sua estrutura de informação segue um padrão com desenho básico delimitando espaços, fontes e disposição de texto pré-definidos.

Acredita-se também ser necessário, como perspectiva futura, após a divulgação deste trabalho, continuar com a pesquisa, tendo em vista alcançar uma quantidade mais expressiva participantes, estendendo a coleta de dados a outros grupos de servidores e professores, como também aos alunos da instituição, a fim de avaliar como estes outros grupos reagem diante das atividades propostas.

\section{REFERÊNCIAS BIBLIOGRÁFICAS}

ABRAHAO, Júlia Issy; PINHO, Diana Lúcia Moura. As transformações do trabalho e desafios teóricometodológicos da Ergonomia. Estud. psicol. (Natal), Natal, v. 7, n. spe, 2002 . Disponível em <http://www.scielo.br/scielo.php?script=sci_arttext\&pid=S1413-294X2002000300006\&lng=en\&nrm=iso>. Acesso em: 23 nov. 2015. http://dx.doi.org/10.1590/S1413-294X2002000300006.

ASSOCIAÇÃO BRASILEIRA DE NORMAS TÉCNICAS. NBR: 9241-11: Requisitos Ergonômicos para Trabalho de Escritórios com Computadores: parte 11 - orientações sobre usabilidade. Rio de Janeiro, 2002.

ALVES, Ana Paula Meneses. Periódicos científicos eletrônicos: reflexões sob o viés CTS. 2010. 203 f. Dissertação (Mestrado em Ciência, Tecnologia e Sociedade) - Centro de Educação e Ciências Humanas, Universidade Federal de São Carlos, São Paulo, 2010. Disponível em: <http://www.bdtd.ufscar.br/htdocs/tedeSimplificado//tde_busca/arquivo.php?codArquivo=3429>. Acesso em: 19 nov. 2014.

BENYON, David. Interação humano-computador. 2.ed. São Paulo: Pearson Prentice Hall, 2011.

BIBLIOCANTO, 2011. Disponível em:< http://periodicos.ufrn.br/bibliocanto>. Acesso em: 29 nov. 2014.

CYBIS, Walter Otto; BETIOL, Adriana Holtz; FAUST, Richard. Ergonomia e usabilidade: conhecimentos, métodos e aplicações. 2. ed. rev. e ampl. São Paulo: Novatec, 2010. 


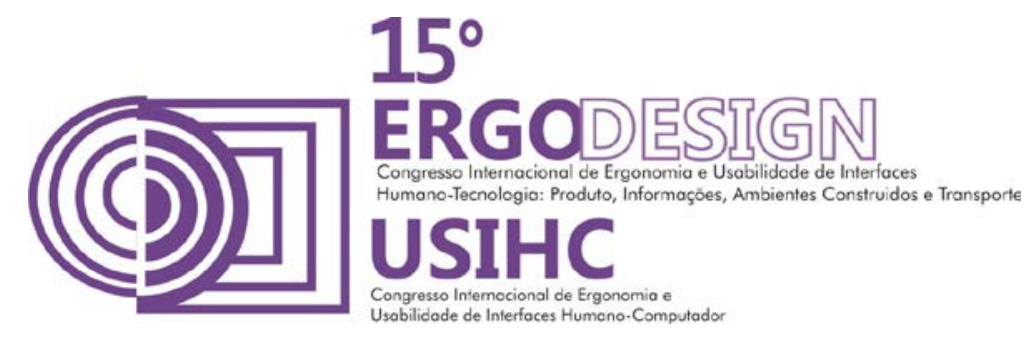

FERREIRA, Ana Gabriela Clipes; CAREGNATO, Sônia Elisa. A editoração eletrônica de revistas científicas brasileiras: o uso de SEER/OJS. TransInformação. Campinas, v. 26, n.2, p.177-190, maio/ago., 2008. Disponível em:< http://www.scielo.br/pdf/tinf/v20n2/05.pdf>. Acesso em: 21 nov. 2014.

LOWDERMILK, Travis. Design centrado no usuário. São Paulo: Novatec, 2013.

MACEDO-ROUET, Mônica. Legibilidade de revistas eletrônicas de divulgação científica. Ciência da Informação. Brasília, v. 32, n. 3, p. 103-112, set./dez. 2003. Disponível em: <http://www.scielo.br/pdf/ci/v32n3/19029.pdf>. Acesso em: 22 nov. 2014.

MACKENZIE, I Scott. Human-Computer Interaction: an empirical research perspective. San Francisco: Morgan Kaufmann, 2012.

MORVILLE, Peter; ROSENFELD, Louis. Information Architecture for the World Wide Web. 3 ed. Sebastopol: O'Reilly Media, 2006.

NIELSEN, Jacob. Usability Engineering. Londres: Academic Press Limited, 1993

NORMAN, Donald A. O design do dia-a-dia. Rio de Janeiro: Rocco, 2006.

PORTAL DE PERIÓDICOS ELETRÔNICOS DA UFRN, 2010. Disponível em:<periodicos.ufrn.br>. Acesso em 29 nov. 2014.

ROSETTO, Marcia. A comunicação científica e as ações para o acesso livre e universal. Boletim do Portal de Revistas Eletrônicas da PUC-SP. n. 2, p. 8-15, 2013. Disponível em: <http://revistas.pucsp.br/index.php/acessoaberto/article/view/13651/10149>. Acesso em 22 nov. 2014.

Os novos materiais bibliográficos e a gestão da informação: livro eletrônico e biblioteca eletrônica na América Latina e Caribe. Ciência da Informação. v. 26 n. 1 Brasília, jan./abr. 1997. Disponível em: <http://www.scielo.br/scielo.php?script=sci_arttext\&pid=S010019651997000100008\&lang=pt>. Acesso em 22 nov. 2014.

RUBIN, Jeffrey. Handbook of Usability Testing. New York: John Wiley and Sons; 1994.

SHNEIDERMAN, Ben. Designing the user interface: strategies for effective human-computer interaction. New York: Addison-Wesley, 1997. 